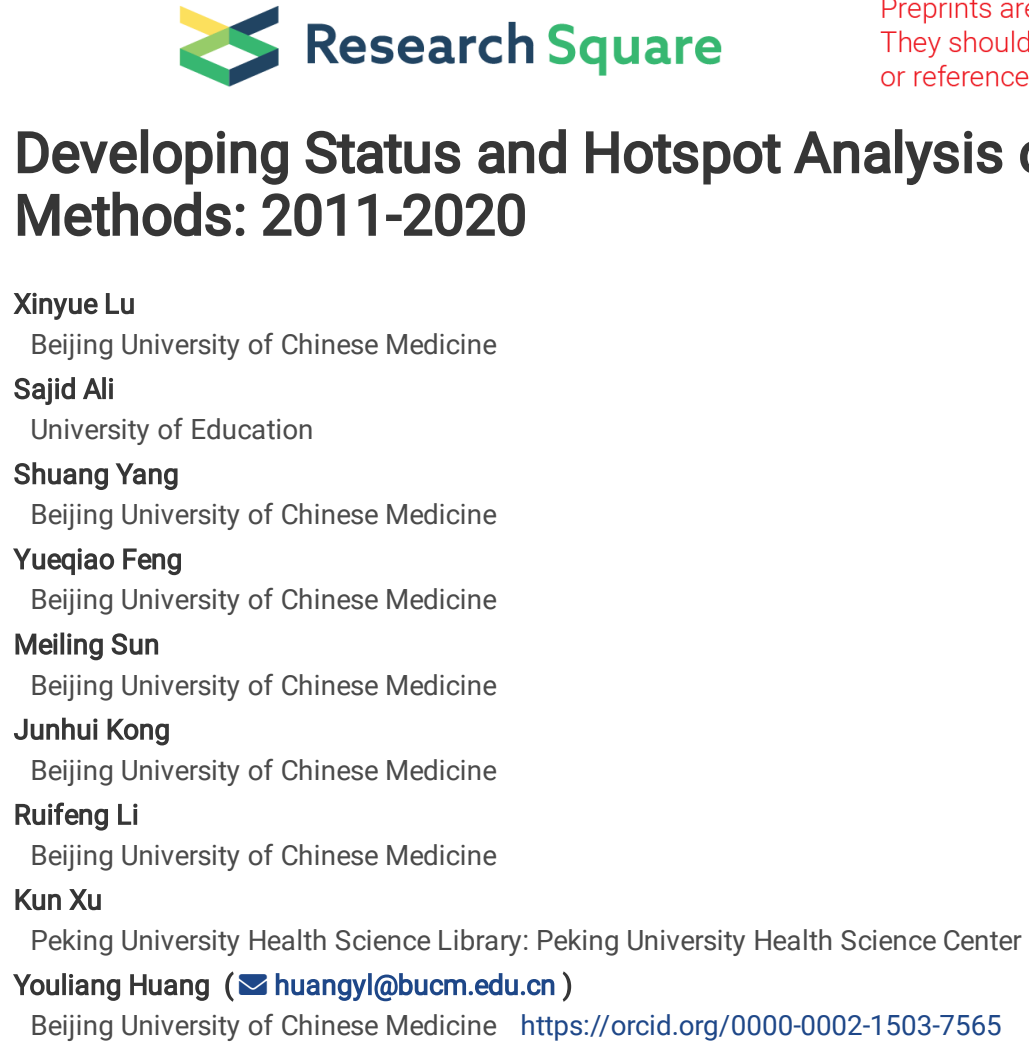

\title{
Developing Status and Hotspot Analysis of Health Policy With Bibliometrics Methods: 2011-2020
}




\section{Abstract}

Objectives: This study mainly discusses the developing status in the field of health policy in recent two decades to provide an effective reference for researchers.

Methods: Health policy publications published in Web of Science between 2011 to 2020 were searched, screened, organized, and analyzed the yearly-outputs, research author, institution, regional distribution, keywords, subject categories, and so on.

Results: The total number of publications in health policy has shown a trend of upward in the past twenty years. Health policy was identified as the most productive journal. The research of United States takes the lead in this field. Health care, public health, epidemiology, children, and quality of life will likely to take a dominant position in future research.

Conclusion: The field of health policy has developed a stable research community with good partnerships, and the high-impact authors lead the development of the discipline. The hotspots of health policy research are constantly updated with the trend of social development and have strong timeliness. With constantly study, health policy has become a relatively mature research topic, but it doesn't mean the termination of the study. It remains to be properly explored and improved to protect people's health and promote the quality of life in the future.

\section{Introduction}

Health policy refers to decisions, plans, and actions that are undertaken to achieve specific health care goals within a society according to World Health Organization. The specific health policy can determine a nice vision for the future, and then in turn help to confirm objectives and reference points for the short and medium-term. Health policy is guided by beliefs and values about humans and health (Alligood \& Miles, 2011). It summarizes matters of priority and the prospective roles of different organizations, establishes consensus and informs people. Health policy is the sum of miscellaneous tools aimed at dealing with specific public health issues and achieving definite health work goals (Willson, 2020). The importance of strengthening the improvement and establishment in health policy research has been increasingly emphasized. It performs important social functions, such as developing academic medicine, adjusting the allocation of health resources, coordinating the interests of relevant groups, and driving social development. Countries around the world accept that health is a basic human right, define the purpose of medicine as the maintenance of health (Hart, Larson, \& Lishner, 2005). Therefore, the formulation of health policies in various countries revolves around the goal of improving health and regard increased equity and access to health as a fundamental starting point (Davis \& Howden-Chapman, 1996). The formulation and implementation of health policies cannot be accomplished in a short period (Flisher et al., 2007) which needs extensive publicity campaigns, persuasion, and education to achieve the goal.

Bibliometrics was first proposed by Pritchard (Hong, He, Nguyen, Liu, \& Zhuang, 2013). Bibliometrics is an applied science that systematically contributes to appraising the importance and status of scientific publications in a designated field (Huang et al., 2016). As an applied tool, it can evaluate the contribution of the scientific productions to the development of research within a specific country, region, or topic (Yang, Zhou, \& Wang, 2013) and be widely used to explore current research trends. It provides a research method for the geographical distribution, topic evolution, hot trends, and so on of a particular domain (Chiu \& Ho, 2007; W.GLANZEL, A.SCHUBERT, \& H.-J.CZERWON, 1999). It has been used to evaluate the scientific outputs, study patterns of institutions, journals, authors, and territories or research trends and hotspots. In the past several years, bibliometrics has been applied to document statistics in different fields.

The study would provide bibliometric analysis and research trends with substantive discussion in health policy research between 2011 and 2020 . The goals of this study are: (1) summarizing publication patterns for institutions, subject categories, and countries in health policy; (2) assessing research performance of author, institution, nation, and journal from diversiform angles; (3) generalizing research areas, global research trends and hot issues to serve as a significative reference for relevant researches.

The study structure is as follows: Materials and methods section describes the whole process of research design, covering data sources, retrieval strategies, cleaning criteria, and relevant analysis. The result and discussion section shows the evaluation conclusion and provoking thoughts. The last section summarizes the main conclusion and the limitations of this study.

\section{Materials And Methods}

Data source and search strategy

Web of Science (WOS), as a significant database for access to global academic information, contains more than 18000 authoritative and influential journals. This database covers multidisciplinary research fields, which divides articles into 256 subject categories. Catalog searching, keywords searching and code searching are the most general searching approaches. This study selected Web of Science as the data source. Under the guidance of experts in related fields, two research workers independently search for documents based on the subject term: health policy.

Inclusion criteria and exclusion criteria

A series of inclusion criteria and exclusion criteria related to the topic, category, content, and period are established to guide publication retrieval and screening. The inclusion criteria the study implemented were as follows:(1) Productions in the field of health policy research; (2) being published between 1st January 2011 and 31 December 2020; (3) database is confined to WOS. The exclusion criteria were the following: (1) repetitive research articles; (2) paper information is required; (3) article needed manual searches; (4) some corrections file. Figure 1 shows the whole process that we identify and screen the publications in this study. 


\section{Data analysis}

In this study, 11632 selected publications were imported and analyzed with some professional document analysis software, such as CiteSpace $V$ Vos Viewer. Relevant publications were analyzed according to the following indicators: (1) publications quantity and overall change trend; (2) language of publications; (3) The most productive institution, country and author; (4) references with high citation and visualization analysis; (5) research hotspot.

\section{Results}

In this study, this study used bibliometrics analysis and visualization approach to analyze the number and quality of published articles about health policy. The results were presented in the form of designed charts and visual maps.

Yearly research publications

To some extent, the chart about the annual distribution trend of publication quantity can reveal the research status in a certain field. During the retrieval process, we find the number of publications didn't show a relatively stable trend before 2011, which can't meet the requirements of bibliometrics research. This phenomenon may be related to the values of giving priority to economy in the world, especially in the developing countries. From 2011 to 2020 , the total number of 11632 publication articles was indexed in the database. It can be indicated from Fig. 2 that the annual number of publications has reached a plateau overall and shown an upward trend from 2011 to 2020. We found there was a high correlation between the annual cumulative number of publications and year [correlation coefficient $\left(\mathrm{R}^{2}\right)=0.994$ ]. The fitted curve was $Y=22.45 X^{2}-2.25 E+06(\mathrm{Y}$ is the annual cumulative number of publications, $\mathrm{x}$ is the publication year) which can predict the future trend of publication numbers. Therefore, it can be assumed that the research and application of health policy are arising in the world and the number of articles related to this field will maintain stable uptrend in the future. The researchers believe that after the outbreak of COVID-19, the world and research institutes will pay more attention to the study of health policy to protect people's right to health and promote the further development of the discipline.

Languages and types of publication

The 11632 publications indexed from 2011 to 2020 can be divided into 10 different document types. It can be concluded that Article has the maximum number of 9 104, comprising $74.00 \%$ of the total number of documents, followed by Review (1 265, 10.28\%), Editorial Material (956, 7.77\%), Meeting Abstract $(745,6.06 \%)$, Proceedings Paper (109, 0.89\%). The data indicate Article and Review made up the major types of documents related to health policy, which accorded with the distribution of reference types characteristics in bibliometric research (Zhi \& Ji, 2012).

For languages analysis, there have been 40 languages used in the 11632 articles, among which English accounted for the largest proportion by 9953 articles (91.35\%), and followed by Portuguese (197, 1.81\%), German (174, 1.60\%), Spanish (135, 1.24\%), French (110, 1.01\%), Korean (89, 0.82\%). The result indicates that English is s-till the most significant language and most widely used in this field. It may be because English is used as the official language by many countries and research institutions.

\section{Countries/Territories}

This study can have a general understanding of the scientific research capacity over a particular field of a country from the national statistics. The number of publications was regarded as the main indicator to analyze the distribution of publications by countries/territories. From 2011 to 2020 , a total of 175 countries/territories published articles and got involved in this study. The USA led the publication quantity ranking of countries with 4176 (38.32\%). The other 9 countries/territories with the relatively high number of articles were England (1 771, 16.26\%), Australia (1 195, 10.97\%), Canada (1 010, 9.27\%), Germany (497, 4.56\%), Netherlands (466, 4.28\%), France (390, 3.59\%), Switzerland (350, 3.21\%), Brazil (345, 3.17\%), China (339, 3.11\%). Among the top 10 countries/territories with the largest number of publications, there is one South American country, one Oceania country, one Asia country, two South American countries and five European countries. Figure 3 shows the global distribution of countries' published articles. We can conclude that Europe and North America are leaders in this field, especially in Europe. It is probably because Europe's medical technology and level are in the leading position around the world.

The study can have a general understanding of the scientific research capacity over a particular field of a country from the national statistics. The number of publications was regarded as the main indicator to analyze the distribution of publications by countries/territories. From 2011 to 2020 , a total of 175 countries/territories published articles and got involved in this study. The USA led the publication quantity ranking of countries with 4176 (38.32\%). The other 9 countries/territories with the relatively high number of articles were England (1 771, 16.26\%), Australia (1 195, 10.97\%), Ca-nada (1 010, 9.27\%), Germany $(497,4.56 \%)$, Netherlands $(466,4.28 \%)$, France (390, 3.59\%), Switzerland (350, 3.21\%), Brazil (345, 3.17\%), China (339, 3.11\%). Among the top 10 countries/territories with the largest number of publications, there is one South American country, one Oceania country, one Asia country, two South American countries and five European countries. Figure 3 shows the global distribution of countries' published articles. We can conclude that Europe and North America are leaders in this field, especially in Europe. It is probably because Europe's medical technology and level are in the leading position around the world.

\section{Most productive journals}

The research found that 1786 journals had published articles in the field of health policy from 2011 to 2020 . Table 1 shows the top ten productive journals which had been publishing $13.437 \%$ of 11632 articles. The journal with the most outputs was "Health Policy" comprising 308 (2.506\%) articles. The following four journals were European Respiratory Journal (303, 2.469\%), BMC Health Services Research (273, 2.221\%), Plos One (229, $1.863 \%)$, Social Science Medicine $(224,1.827 \%)$. Double graph overlay for journals can exhibition distribution and citation trajectory of publications in different subjects from which researchers can have a general idea of basic foundations and application fields. Figure 4 covers two reference paths that indicated the relationship between journals of citing articles and journals of references. In the main body of Fig. 4 the width of the line represented citation strength between two different 
disciplines. The width of the ellipse stands up the number of authors and the height of the ellipse shows the number of publications. It can be indicated that the citing articles in the field of health policy concentrated on Medical and Clinical, and Education and Health. The main references belonged to Molecular and Biology, Nursing and Medicine.

Table 1

10 top journals with most publications

\begin{tabular}{|llll|}
\hline Rank & Journal & TP (\%) & IF(2020) \\
\hline 1 & Health Policy & $308(2.506)$ & 1.774 \\
\hline 2 & European Respiratory Journal & $303(2.469)$ & 12.339 \\
\hline 3 & BMC Health Services Research & $273(2.221)$ & 1.987 \\
\hline 4 & Plos One & $229(1.863)$ & 2.740 \\
\hline 5 & BMC Public Health & $224(1.827)$ & 2.521 \\
\hline 6 & Journal of Public Health Policy & $208(1.689)$ & 1.500 \\
\hline 7 & BMJ Open & $193(1.570)$ & 2.496 \\
\hline 9 & International Nursing Review & $172(1.395)$ & 2.034 \\
\hline 10 & Circulation & $166(1.349)$ & 23.603 \\
\hline TP: the number of total articles IF: impact factor & \\
\hline
\end{tabular}

Most productive institutions

A total of 1003 research institutions were involved in the publication work of 11632 articles. The research-based the quantity and quality of institution publications can help us identify and analyze the most high-impact institutions. The top 10 institutions ranked according to the number of publications are showed Table 2 shows. In the top 10 institutions, four institutions are in the United States, three in the United Kingdom, two each in Switzerland and Australia. The most productive institution is the University of London in United Kingdom, occupying $4.846 \%$ of all records. Among the top ten institutions, 9 are higher education institutions. The result indicates the higher education institutions are the main position in the field of scientific research.

Table 2

The 10 most-active institutions with the number of articles

\begin{tabular}{|llll|}
\hline Rank & Institution & TP (\%) & Country \\
\hline 1 & University of LonDon & $528(4.846)$ & United Kingdom \\
\hline 2 & Harvard University & $392(3.598)$ & United States \\
\hline 3 & University of California System & $349(3.203)$ & United States \\
\hline 4 & World Health Organization & $277(2.542)$ & Switzerland \\
\hline 5 & LonDon School of Hygiene Tropical Medicine & $253(2.322)$ & United Kingdom \\
\hline 6 & Johns Hopkins University & $218(2.001)$ & United States \\
\hline 7 & University of Toronto & $217(1.992)$ & Canada \\
\hline 8 & University of Sydney & $182(1.670)$ & Australia \\
\hline 9 & London Sch Hyg Trop Med & $162(1.487)$ & United Kingdom \\
\hline 10 & Harvard T.H. Chan School of Public Health & $153(1.404)$ & United States \\
\hline TP: the number of total articles & & \\
\hline
\end{tabular}

High-impact authors

The top 10 authors on the basis of publications number are summarized in Table 3. McKee Martin was the highest productivity author who had 39 outputs between 2011 and 2020. McKee Martin's research related to public health had a significant influence on the other authors. Several other influential authors in this field are Andrew B. Rosenkranz, Duszak, Richard, Jr., Fonarow, Gregg C., Krumholz, Harlan M. High-impact authors usually have special guidance for a particular field of research. Their researches will directly or indirectly influence hotspots and trends, which will provide theoretical support and ideas for other researchers. 
Table 3

The 10 most-productive authors

\begin{tabular}{|lllll|}
\hline Rank & Author & Publications number & Institution & Country \\
\hline 1 & McKee Martin & 39 & London School of Hygiene \& Tropical Medicine & United Kingdom \\
\hline 2 & Andrew B. Rosenkranz & 28 & New York University & United States \\
\hline 3 & Duszak, Richard, Jr. & 26 & Emory University & United States \\
\hline 5 & Fonarow, Gregg C. & 26 & University of California Los Angeles Ahmanson & United States \\
\hline 6 & Lavis, John N. & 24 & Yale University & United Kingdom \\
\hline 7 & Steiner, Timothy J. & 23 & McMaster Health Forum & Canada \\
\hline 8 & Peterson, Eric D. & 22 & Norwegian University of Science \& Technology (NTNU) & Norway \\
\hline 10 & Mackey, T. K. & 20 & Duke University & United States \\
\hline Gigh-cited article & 19 & University of California System & United States \\
\hline
\end{tabular}

The Price Law is always used to identify the high-impact authors and articles in the area of bibliometrics (Golden Shelley et al., 2020). According to the Price Law, it can be concluded that those covered with Times Cited 42 are highly cited articles $(M p=6.95, N p m a x=86)$. The statistical data shows that there are 243 highly cited articles. The most frequently-cited 10 articles content is showed in Table 4. The top 10 high-impact publications were published in 6 different journals, among which the Lancet ( 5 articles, $50 \%$ ) occupied the highest proportion. It can be indicated that the Lancet had a great contribution to the research in this area between 2011 to 2020. The most frequently-cited article was 'Population-based study of health service deficits in US adults with depression: Does chronic disease co-morbidity and/or rural residency make a difference?' written by Andrine Lemieux and Daniel M. Saman in 2013. This publication was cited 86 times totally from 2011 to 2020 . Figure 5 shows the high-cited Articles and document co-citation network.

Distribution by Web of Science category

Journals are divided into different subject categories based on subjects in WOS, in which all articles are published in 178 different subjects. 11632 articles are divided into 141 different subject categories. Figure 6 displays the top 10 subject categories with the largest number of productions. The result indicates the Public Health is strongly inked to plenty of subject categories, such as Public, Environmental \& Occupational Health, Health Care Sciences Services, General Internal Medicine, and so on. Health policy is a comprehensive study that involved a lot of cooperation with other area classification. It encourages related researchers to conduct some think and discussion from multiple angles and subjects' traits. Meanwhile, health policy is still a research hotspot in the future.

Table 4 The Top 10 highly papers 


\begin{tabular}{|c|c|c|c|c|c|c|c|c|c|}
\hline \multirow{6}{*}{$\begin{array}{l}\text { Table } 4 \\
\text { The } \\
\text { Top } 10 \\
\text { highly } \\
\text { papers }\end{array}$} & Times & 86 & 55 & 45 & 44 & 44 & 41 & 39 & 39 \\
\hline & Year & 2013 & 2012 & 2008 & 2008 & 2014 & 2012 & 2011 & 2015 \\
\hline & Journal & Lancet & Lancet & $\begin{array}{l}\text { Health Policy } \\
\text { and Planning }\end{array}$ & $\begin{array}{l}\text { Health } \\
\text { Policy } \\
\text { Plan }\end{array}$ & $\begin{array}{l}\text { BMC Health Serv } \\
\text { Res }\end{array}$ & Lancet & Plos One & Lancet \\
\hline & Author & $\begin{array}{l}\text { Andrine } \\
\text { Lemieux, } \\
\text { Daniel M. } \\
\text { Saman, M. } \\
\text { Nawal } \\
\text { Lutfiyya }\end{array}$ & $\begin{array}{l}\text { LimSS, } \\
\text { VosT, } \\
\text { FlaxmanAD }\end{array}$ & $\begin{array}{l}\text { Walt, Gill, } \\
\text { Jeremy } \\
\text { Shiffman, Helen } \\
\text { Schneider, } \\
\text { Susan F. a }\end{array}$ & $\begin{array}{l}\text { Gilson L, } \\
\text { Raphaely } \\
\text { N }\end{array}$ & $\begin{array}{l}\text { Oliver K, Innvar S, } \\
\text { Lorenc T }\end{array}$ & $\begin{array}{l}\text { VosT, } \\
\text { FlaxmanAD, } \\
\text { NaghaviM }\end{array}$ & $\begin{array}{l}\text { Lois Orton } \\
\text { Ffion, Lloyd } \\
\text { Williams, } \\
\text { David }\end{array}$ & $\begin{array}{l}\text { Global Burden } \\
\text { of Disease } \\
\text { Study } 2013 \\
\text { Collaborators }\end{array}$ \\
\hline & Title & $\begin{array}{l}\text { Population- } \\
\text { based } \\
\text { study of } \\
\text { health } \\
\text { service } \\
\text { deficits in } \\
\text { US adults } \\
\text { with } \\
\text { depression: } \\
\text { Does } \\
\text { chronic } \\
\text { disease co- } \\
\text { morbidity } \\
\text { and/or } \\
\text { rural } \\
\text { residency } \\
\text { make a } \\
\text { difference? } \\
\text { (Lemieux, } \\
\text { Saman, \& } \\
\text { Lutfiyya, } \\
\text { 2013) }\end{array}$ & $\begin{array}{l}\text { A } \\
\text { systematic } \\
\text { analysis for } \\
\text { the Global } \\
\text { Burden of } \\
\text { Disease } \\
\text { Study } \\
2010(\mathrm{R} . \\
\text { Lozano, } \\
\text { Naghavi, } \\
\text { Foreman, } \\
\text { Lim, \& } \\
\text { Aboyans) }\end{array}$ & $\begin{array}{l}\text { Doing' Health } \\
\text { Policy Analysis: } \\
\text { Methodological } \\
\text { and Conceptual } \\
\text { Reflections and } \\
\text { Challenges(Walt } \\
\text { et al., 2008) }\end{array}$ & $\begin{array}{l}\text { The } \\
\text { terrain of } \\
\text { health } \\
\text { policy } \\
\text { analysis } \\
\text { in low and } \\
\text { middle } \\
\text { income } \\
\text { countries: } \\
\text { a review } \\
\text { of } \\
\text { published } \\
\text { literature } \\
\text { 1994- } \\
\text { 2007(Lucy } \\
\text { \& Nika, } \\
\text { 2008) }\end{array}$ & $\begin{array}{l}\text { A systematic review } \\
\text { of barriers to and } \\
\text { facilitators of the } \\
\text { use of evidence by } \\
\text { policymakers(Oliver, } \\
\text { Innvar, Lorenc, } \\
\text { Woodman, \& } \\
\text { Thomas, 2014) }\end{array}$ & $\begin{array}{l}\text { Years lived } \\
\text { with } \\
\text { disability } \\
\text { (YLDs) for } \\
1160 \\
\text { sequelae of } \\
289 \\
\text { diseases } \\
\text { and injuries } \\
\text { 1990- } \\
\text { 2010: a } \\
\text { systematic } \\
\text { analysis for } \\
\text { the global } \\
\text { burden of } \\
\text { disease } \\
\text { study 2010 } \\
\text { ("Years } \\
\text { lived with } \\
\text { disability } \\
\text { (YLDs) for } \\
\text { 1160 } \\
\text { sequelae of } \\
289 \\
\text { diseases } \\
\text { and injuries } \\
1990- \\
2010: \text { a } \\
\text { systematic } \\
\text { analysis for } \\
\text { the Global } \\
\text { Burden of } \\
\text { Disease } \\
\text { Study } \\
2010, " \\
2012 \text { ) }\end{array}$ & $\begin{array}{l}\text { The Use of } \\
\text { Research } \\
\text { Evidence in } \\
\text { Public Health } \\
\text { Decision } \\
\text { Making } \\
\text { Processes: } \\
\text { Systematic } \\
\text { Review(Orton, } \\
\text { Lloyd- } \\
\text { Williams, } \\
\text { Taylor- } \\
\text { Robinson, } \\
\text { O'Flaherty, \& } \\
\text { Capewell, } \\
\text { 2011) }\end{array}$ & $\begin{array}{l}\text { Global, } \\
\text { regional, and } \\
\text { national } \\
\text { incidence, } \\
\text { prevalence, } \\
\text { and years } \\
\text { lived with } \\
\text { disability for } \\
301 \text { acute and } \\
\text { chronic } \\
\text { diseases and } \\
\text { injuries in } 188 \\
\text { countries, } \\
\text { 1990-2013: a } \\
\text { systematic } \\
\text { analysis for } \\
\text { the Global } \\
\text { Burden of } \\
\text { Disease Study } \\
2013 \\
\text { (Collaborators, } \\
\text { 2018) }\end{array}$ \\
\hline & Rank & 1 & 2 & 3 & 4 & 5 & 6 & 7 & 8 \\
\hline
\end{tabular}

Hotspot keywords analysis

Foam Tree was generated by Carrit2, which is an open search-based clustering engine. This study chose "Lingo" as the clustering algorithm and got Fig. 7. The size of the polygon represents the frequency of different topics. As Fig. 7 shown, Evidence Review was the most common research approach in this field. Changes in health policy and disease policy have aroused researchers' wide concern.

The keywords of articles are phrases or words extracted from the body, title, or abstract that can reveal the theme of the scientific papers. The research method of keywords was first used by Chiu and Ho for bibliometrics research to find a sally port for study trends and development (Sorensen \& Aaron, 2009). Figure 8 shows the result of the keyword co-appearance network, in which the size of keywords represents its word frequency. The research adopted the word frequency analysis to extract the core content of the publications and study the hotspots in this field. Figure 8 shows the top 10 keywords ranked by the word frequency. Except search word ('health policy'), the five most frequently appeared and available keywords were Health Care, Public Health, Epidemiology, Children and Quality of life. We can certainly deduce that the research focuses on Health Care Sciences \& Services, Public health, Disease prevention, Epidemic prevention, and cure in the recent 10 years. Specific hot keywords are analyzed as follows:

- Public health

As a contrast to traditional medicine, public health focuses on population health rather than individual patients. Public health is a social service aiming to promote entire health situation and prevent diseases. ( $\mathrm{Ng} \&$ Ruger, 2014) Of course, it also involves the work of demographic surveillance, food hygiene security etc. public health law and public health policy help people reduce health risks, prevent disease, and striving for healthy populations, which are the most fundamental guarantee. (Allan, 2017) Public health policy is usually designated by government departments that represent the medical service goals in a nation. Public health policy has been regarded as the most available approach to reduce public health harms. For example, the Alcohol Harm Reduction Strategy for England acquired great accomplishments in decreasing traffic accidents and public security affairs due to alcohol abuse.(Braillon \& Dubois, 2005) Public health policy adjusts the service orientation with the trends of health indicators to satisfy the health needs of the population. (Soulis, Sarris, Pierrakos, Goula, \& Gkioka, 2015) According to the study result, we can indicate that the research about public health policy will keep focused on the following aspects:1. health promotion (to eliminate the health risk factors, such as obesity, overweight, drinking, smoking, blood pressure, etc.). 2.prevention diseases 
with high mortality (such as coronary-heart-disease, renal disease, etc.). 3.pay more attention to the special crowd (such as pregnant women, elderly people, etc.).

- Health care

Health care always consists of public and private institutions and insurance programs.(None, 1993) Health care is closely correlated with pharmaceutical and healthcare fields, which work to regulate the medical services, preserve the population's health, make basic medical and health services more equitable and accessible and eventually maintain social stability. Health care policy is always considered as decisions, plans and actions adopted to reach specific goals within the society.(Dimick, J., Ryan, \& A., 2014) Health care policy covers several issues related to health, covering the financing of health care, preventive medicine, chronic diseases and disabilities, mental health and long-term care ,etc. Establishing an effective health care policy has become a worldwide problem, which is concerned popularly for the specialists in this field. At present, the urgent problem (hotspot) is to improve penetration and quality of health care across the country.

- Epidemiology

Epidemiology which is considered as the basic science of public health is the research of the distribution and determinants of events, health conditions, or diseases among populations and the application of the study to control health problems. When it comes to epidemiology, the majority of people naturally think of infectious diseases like cholera and AIDS. It concentrates on various health-related situations-diseases (e.g. flu, epidemic hemorrhagic fever, depression), health risks (e.g. high blood pressure, obesity), injuries (e.g. traffic accidents) and some social problems (e.g. taking drugs, gambling). Epidemiology policy plays a significant role in exploring the causes of conditions and preventing them. Prevention and elimination of infection, establishing and improving the public health system will be the priority of work in the study of epidemiology policy.

- Children

Statistics result taken from WHO indicates that Risks to young children health mainly include low birth weight, malnutrition, not breastfeeding, overcrowded conditions, unsafe drinking water and indoor air pollution, overweight/obesity, poor diet physical inactivity including drowning, falls and burns are the main threats for the older children. Children are the vulnerable group in society, whose health and growth conditions caused wide public concern all over the world. The health policy about children will tend to protect not only their physical health but also mental health.

- Quality of life

Life quality obtains multidimensional experience and objective feeling. When people encounter some conditions in their life like job loss, illness etc., they will change the definition of" quality of life". The pursuit of quality of life represents the desire of creating a happy life. Happiness can maintain people's mental health to some extent. The policy concentrating on "quality of life" will adopt some measures such as improving public infrastructure to emphasize the average happiness of population.

Table 5

The top 10 keywords

\begin{tabular}{|llllll|}
\hline Rank & Keyword & Frequency & Rank & Keyword & Frequency \\
\hline 1 & Health policy & 4212 & 6 & Epidemiology & 1030 \\
\hline 2 & Public health & 1662 & 7 & Children & 998 \\
\hline 3 & Health care & 1584 & 8 & United States & 582 \\
\hline 5 & Mortality & 1290 & 9 & Disease & 439 \\
\hline 6 & Epidemiology & 1030 & 10 & Policy & 410 \\
\hline
\end{tabular}

Keywords of bursts

Burst detection can detect large changes in the number of references at a given time. It is available to detect the decline or rise for a particular subject or keyword, which has been applied to our research. Figure 9 shows the top 15 keywords with the strongest bursts from 2011 to 2020 . Initially, 2011 was regarded as the base period. The black line represents the learning period and the red represents the study outbreak period. It can be indicated that the internet, influenza, economics, law, etc. are research hotspots between 2011 and 2014. The changes in research hotspots are often related to the social background and environment. For instance, as the swine flu outbreak reached epidemic (Maria et al., 2012), influenza vaccine safety and the establishment of a public health system become the study hotspot in 2011. With the development of modern technology, online medical care and mental health has become research trends in this field. Some keywords were tending towards stability after a while, which may be because some issues had been solved successfully or the social environments had changed a lot. Figure 9 shows the keywords timeline and cluster graph.

\section{Discussion And Conclusions}

From 2011, the number of yearly-publication has shown a downward trend and been stable eventually. The frequency of publication will maintain this trend in the coming period. There are 10 publication types used by 11632 articles. English is the most significant and most widely used language in the research of health policy. America takes the lead in this field with approximately $38 \%$ of publications. The researches about health policy follow the study model of "international cooperation" and has formed a relatively stable research group. The most productive institution is the University of London in the United 
Kingdom. The study shows that universities are the most important research institutions in this field. At present, the most high-impact author is McKee Martin but there are no opinion leaders in the field who can guide the development of the whole discipline. The 11632 articles published in 1786 journals are divided into 141 different subject categories. The research hot-spot are as following: health care, public health, epidemiology, children, and quality of life.

In conclusion, health policy is closely related to people's life. With constantly study, it has become a relatively mature research topic, but it doesn't mean the termination of the study. It remains to be properly explored and improved. Research in health policy will contribute to every aspect of people's lives as the international community pays more attention to health problems in the future.

\section{Declarations}

Ethics approval and consent to participate

Not applicable

Adherence to national and international regulations

Not applicable

Consent for publication

Not applicable

Availability of data and materials

The datasets analyzed during the current study are available in the Web of Science repository

Competing interests

The authors declare that they have no competing interests

Funding

This work was supported by "the project entrusted by the Fourth National Economic Census Leading Group Office of China" (Grant No. JJPCZB44) and "the Fundamental Research Funds for the Central Universities" (Grant No. 2020-JYB-ZDGG-067). "The project entrusted by the Fourth National Economic Census Leading Group Office of China" supported the design of the research scheme and data collection. "The Fundamental Research Funds for the Central Universities" supported data analysis and report writing. Both foundations agreed to submit this paper.

Authors' contributions

Xinyue Lu and Yueqiao Feng selected the topic and made a detailed schedule. Meiling Sun and Shuang Yang download text data. Xinyue Lu and Sajid Ali carried out the data preprocessing and analyzed the result regarding the health policy. Shuang Yang, Meiling Sun and Yueqiao Feng made the diagrams. Xinyue Lu, Youliang Huang and Junhui Kong were major contributors in writing the manuscript. Kun Xu and Ruifeng Li checked and revised the article. All authors read and approved the final manuscript.

Acknowledgements

The authors acknowledge Web of Science database for providing research data and the two funds for their support.

\section{References}

1. Allan S. (2017). Public health law and public health policy. International Encyclopedia of Public Health, 200-209.

2. Alligood MR, Miles JM. Nursing Knowledge and Health Policy in Process. Nursing Science Quarterly. 2011;24(1):7.

3. Braillon A, Dubois G. Alcohol and public health. Lancet. 2005;365(9468):1387-7.

4. Chiu WT, Ho YS. (2007). Bibliometric analysis of tsunami research. Scientometrics, 73, 3-17. Scientometrics, 73(1), 3-17.

5. Collaborators GB, o. DS. Global, regional, and national incidence, prevalence, and years lived with disability for 301 acute and chronic diseases and injuries in 188 countries, 1990-2013: a systematic analysis for the Global Burden of Disease Study 2013. Lancet. 2018;386(9995):743-800.

6. Davis P, Howden-Chapman P. (1996). Translating research findings into health policy. 43(5), 865-872.

7. Dimick J, B., Ryan, \& A., M. (2014). Methods for evaluating changes in health care policy: The difference-in-differences approach. Jama the Journal of the American Medical Association.

8. Flisher AJ, Lund C, Funk M, Banda M, Bhana A, Doku V,... Omar M. Mental Health Policy Development and Implementation in Four African Countries. J Health Psychol. 2007;12(3):505-16.

9. Golden Shelley D, Kim K, Kong Amanda Y, Tao Vivian Q, Carr D, Musburger P. (2020). Simulating the impact of a cigarette minimum floor price law on adult smoking prevalence in California. Nicotine \& tobacco research: official journal of the Society for Research on Nicotine and Tobacco.

10. Hart LG, Larson EH, Lishner DM. Rural Definitions for Health Policy and Research. Am J Public Health. 2005;95(7):1149-55. 
11. Hong S, He Q, Nguyen T, Liu X, Zhuang Y. (2013). Global remote sensing research trends during 1991-2010. Scientometrics.

12. Huang Y, Huang Q, Ali S, Zhai X, Bi X, Liu R. Rehabilitation using virtual reality technology: a bibliometric analysis, 1996-2015. Scientometrics. 2016;109(3):1547-59.

13. Lemieux A, Saman DM, Lutfiyya MN. Population-based study of health service deficits in US adults with depression: Does chronic disease co-morbidity and/or rural residency make a difference? Health. 2013;5(4):774-82.

14. Lozano R, Naghavi M, Foreman K, Lim S, Aboyans V. A systematic analysis for the Global Burden of Disease Study 2010.

15. Lozano R, Naghavi M, Foreman K, Lim S, Shibuya K, Aboyans V,... Ahn SY. Global and regional mortality from 235 causes of death for 20 age groups in 1990 and 2010: a systematic analysis for the Global Burden of Disease Study 2010. Lancet. 2012;380(9859):2095-128.

16. Lucy G, Nika R. (2008). The terrain of health policy analysis in low and middle income countries: a review of published literature 1994-2007. Health Policy Plan(5), 294-307.

17. Maria dPM, Hamed CWWG,ZV,GKD, loanna A, W S, C. R. (2012). Local response to microneedle-based influenza immunization in the skin. Mbio, 3(2).

18. Moher D, Liberati A, Tetzlaff J, Altman DG (2009). Moher D, Liberati A, Tetzlaff J, Altman DG. Group PPreferred reporting items for systematic reviews and meta-analyses: the PRISMA statement. PLoS Med 6: e1000097. Open Medicine, 3(3), e123-130.

19. Ng NY, Ruger JP. (2014). Ethics and Social Value Judgments in Public Health. Social Science Electronic Publishing, $287-291$.

20. None. Don't rush cataract surgery, expert panel advises - U.S. Public Health Service Agency for Health Care Policy and Research. Ophthalmology. 1993;100(6):iv.

21. Oliver K, Innvar S, Lorenc T, Woodman J, Thomas J. (2014). A systematic review of barriers to and facilitators of the use of evidence by policymakers. Bmc Health Services Research, 14.

22. Orton L, Lloyd-Williams F, Taylor-Robinson D, O'Flaherty M, Capewell S. (2011). The Use of Research Evidence in Public Health Decision Making Processes: Systematic Review. PloS one, 6.

23. Sorensen, Aaron A. Alzheimer's Disease Research: Scientific Productivity and Impact of the Top 100 Investigators in the Field. Journal of Alzheimer।"s Disease. 2009;16(3):451-65.

24. Soulis S, Sarris M, Pierrakos G, Goula A, Gkioka V. Public Health Policies in European Union: An Innovation Strategy-Horizon 2020. Elsevier Inc; 2015.

25. W.GLANZEL, A.SCHUBERT, \& H.-J.CZERWON. (1999). A bibliometric analysis of international scientific cooperation of the European Union (1985-1995). Scientometrics, 45(2), 185-202.

26. Walt G, Shiffman J, Schneider H, Murray SF, Brugha R, Gilson aL. 'Doing' health policy analysis: methodological and conceptual reflections and challenges. Health Policy Planning. 2008;23(5):308-17.

27. Willson PD. (2020). The Importance of Lobbying to Advance Health and Science Policy. Academic Medicine, 95.

28. Yang C, Zhou S, Wang G. A bibliometric analysis of global laparoscopy research trends during 1997-2011. Scientometrics. 2013;96(3):717-30.

29. Years lived with disability (YLDs) for 1160 sequelae of 289 diseases and injuries 1990-2010: a systematic analysis for the Global Burden of Disease Study 2010. (2012). Lancet.

30. Zhi W, Ji G. Constructed wetlands, 1991-2011: A review of research development, current trends, and future directions. Sci Total Environ. 2012;441(DEC.15):19-27.

\section{Figures}




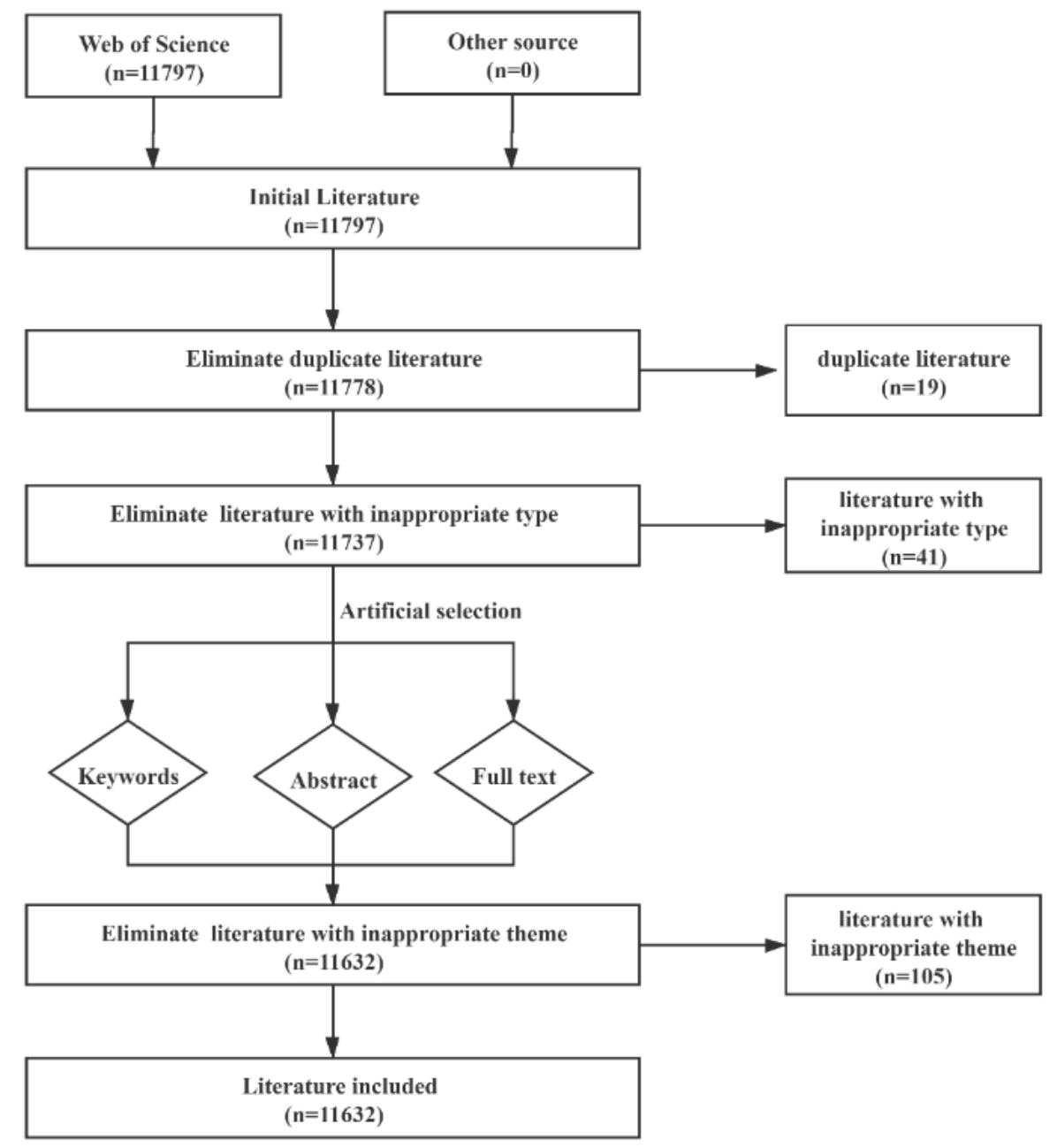

\section{Figure 1}

The Search Strategy Diagram

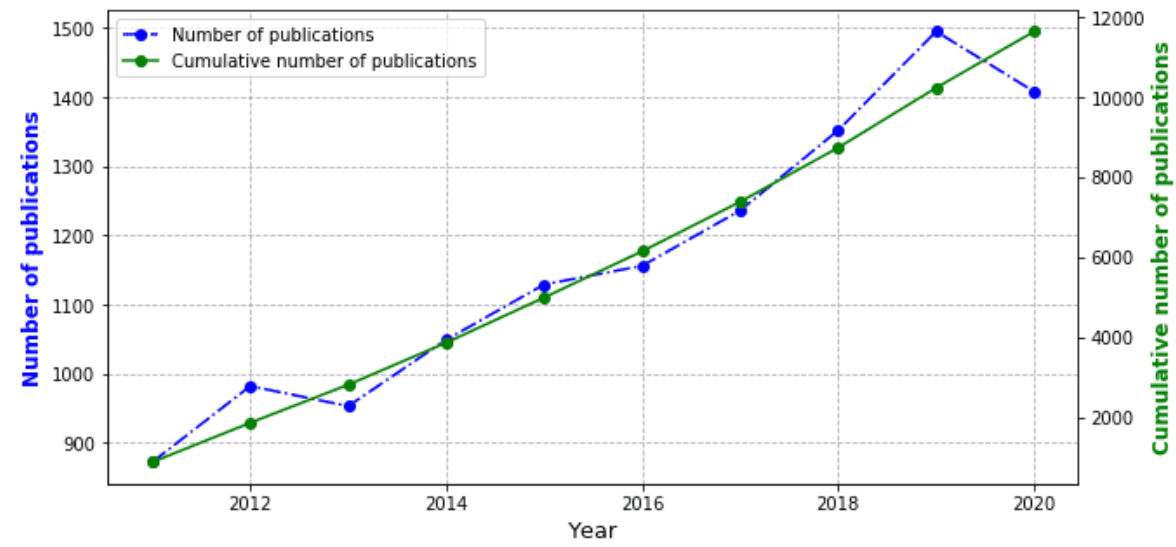

Figure 2

The Number/Cumulative Number of publications 


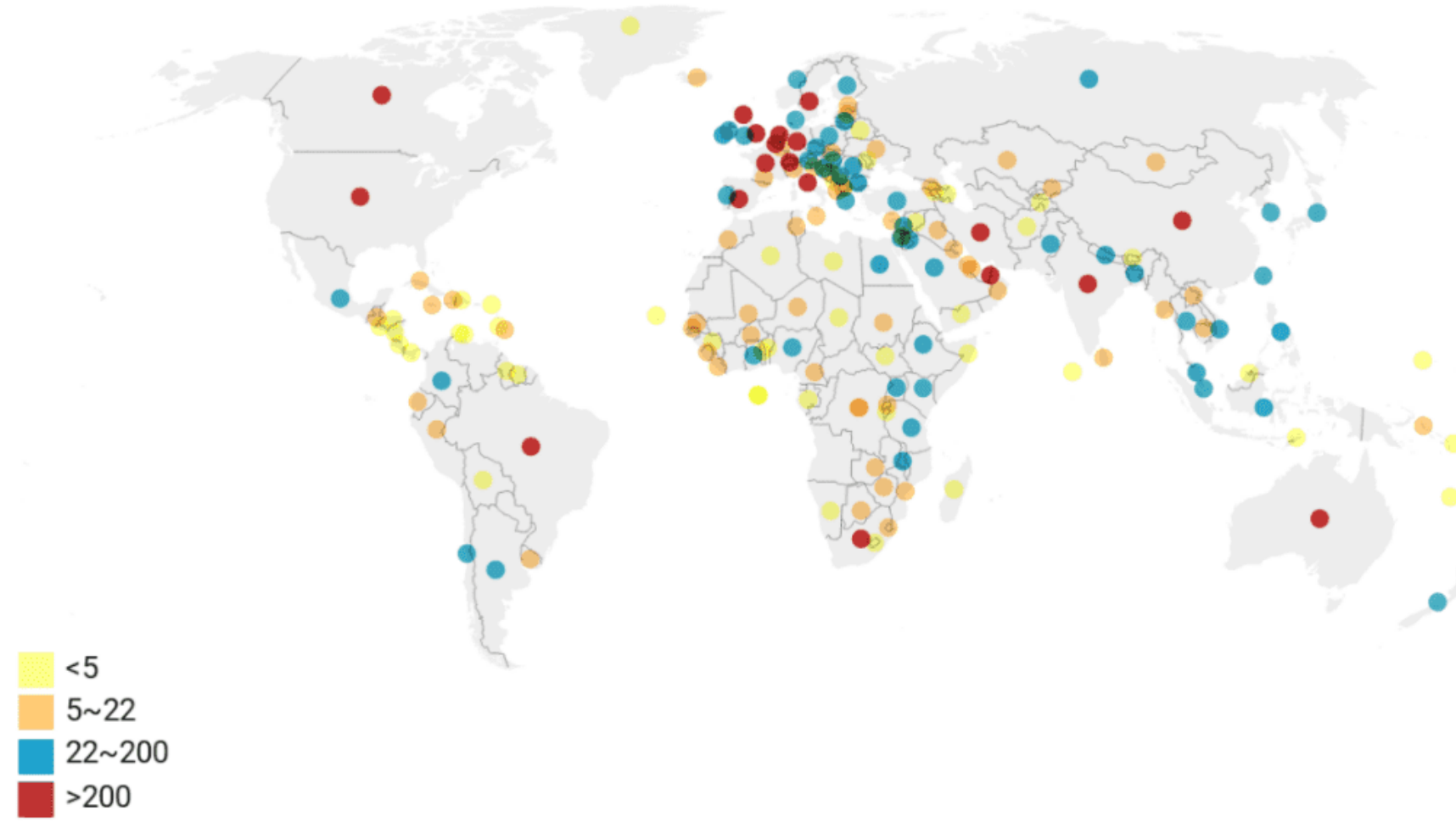

Figure 3

Distribution of articles published in the countries/territories

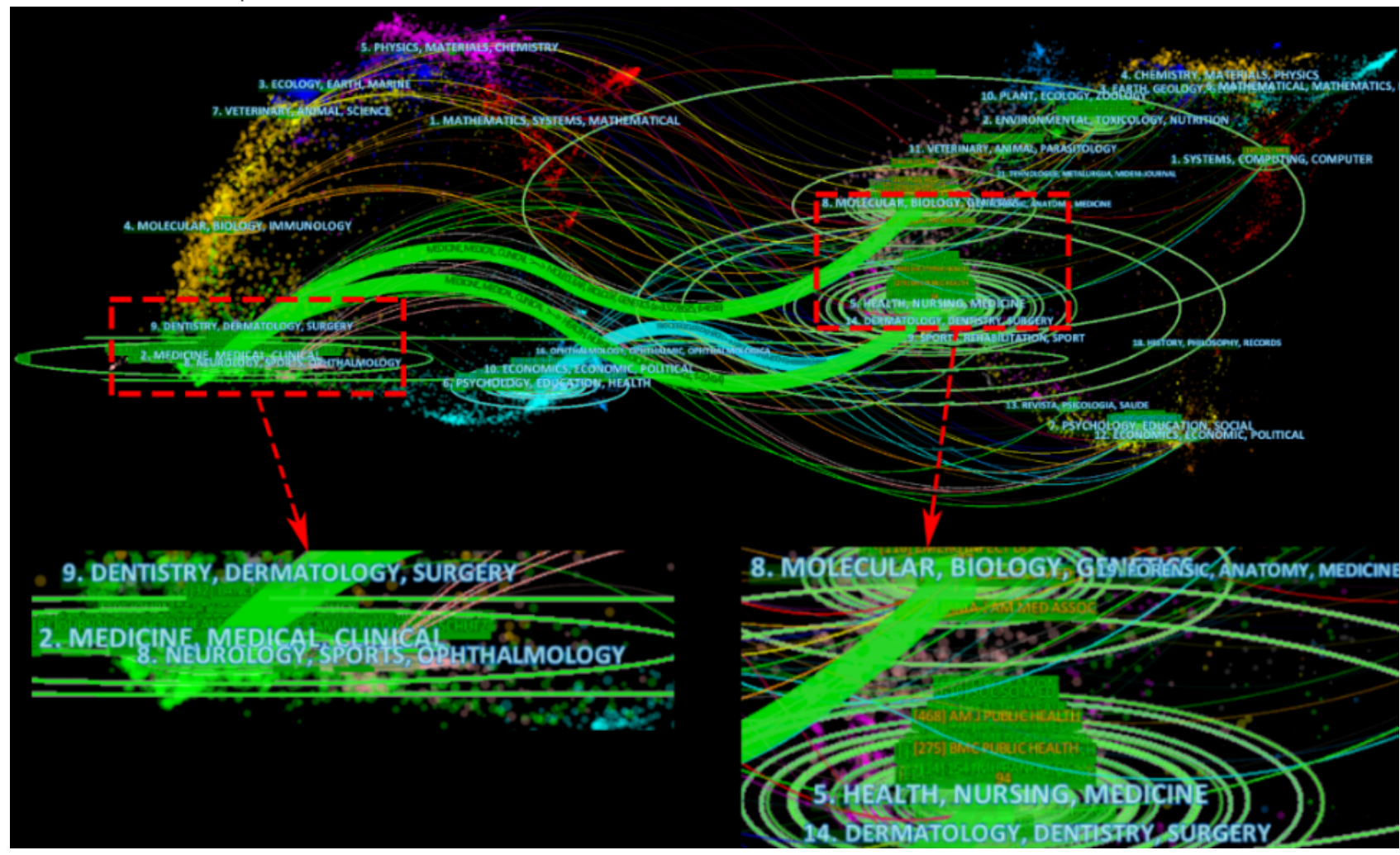

Figure 4

Double graph overlay for journals covering two reference paths, the left were the journals of citing articles, the right were the journals of reference 


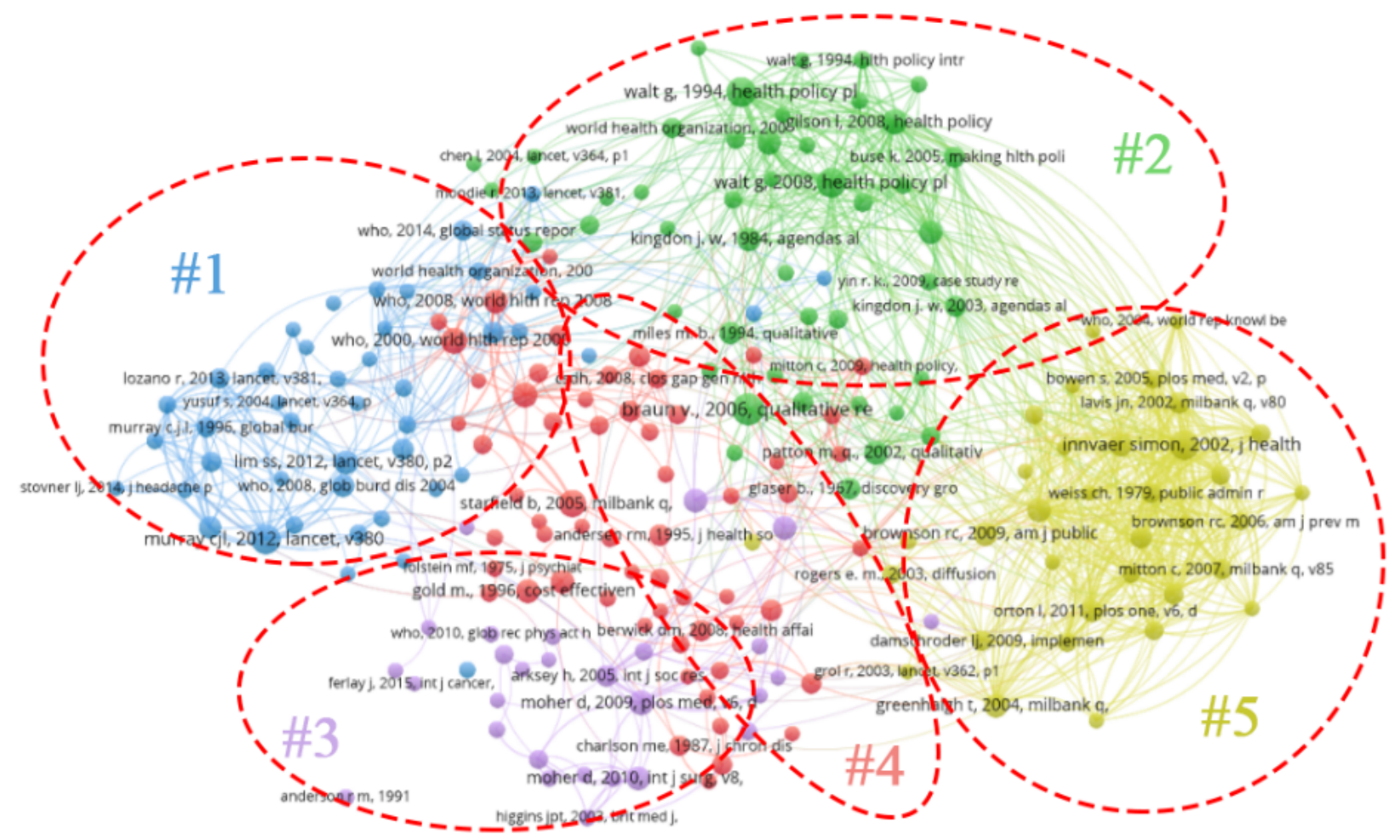

Figure 5

document co-citation network

\section{[ Insert title here ]}

Public environmental occupational health

Health care sciences services

General internal medicine

Nursing

Cardiovascular system cardiology

Biomedical social sciences

Psychiatry

Respiratory system

Infectious diseases

Oncology

\section{2,968}

2,455

1,333

674

471

396

380

352

303

289

Created with Datawrapper

Figure 6

the top 10 subject area 


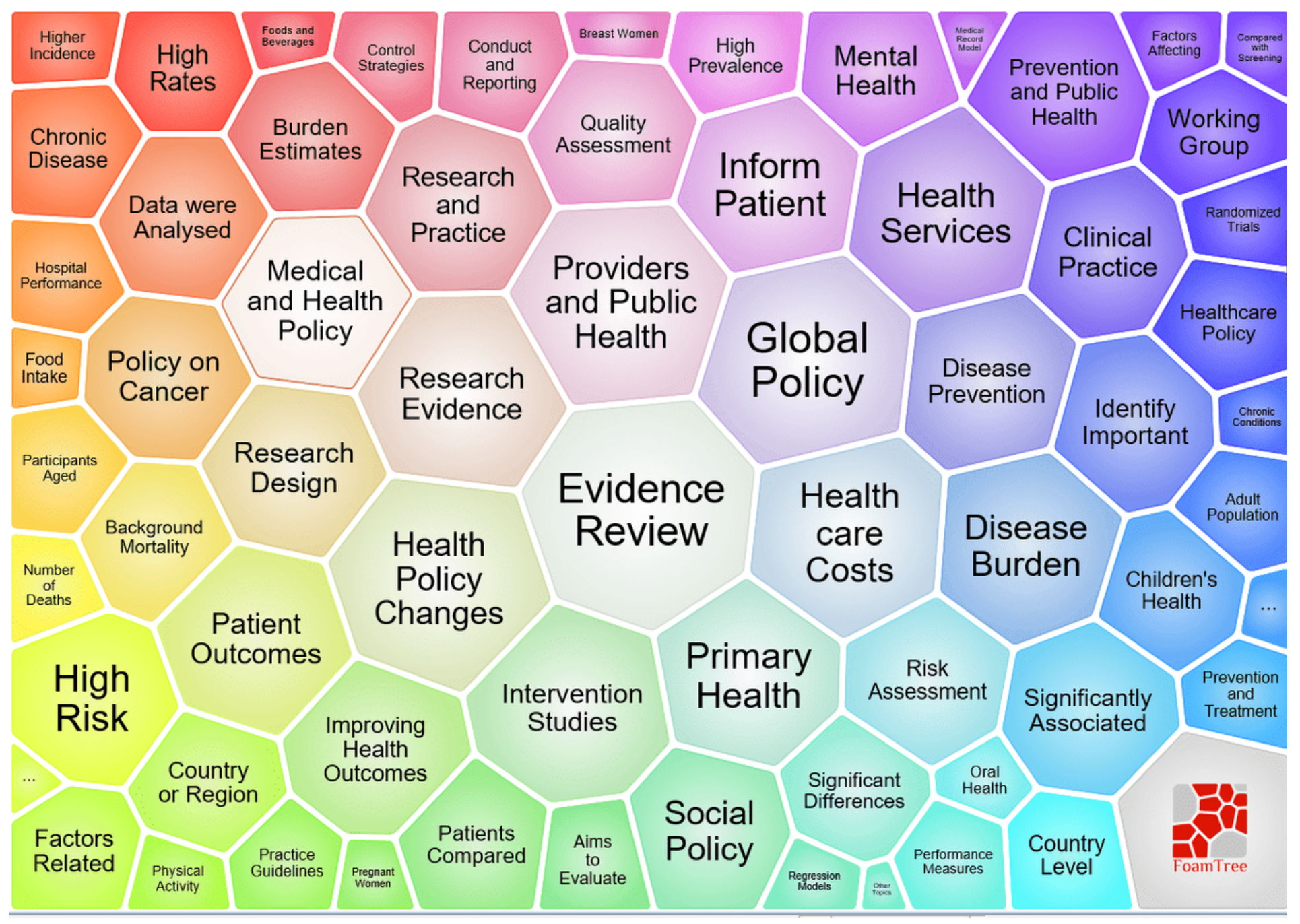

Figure 7

Foam Tree visualization 


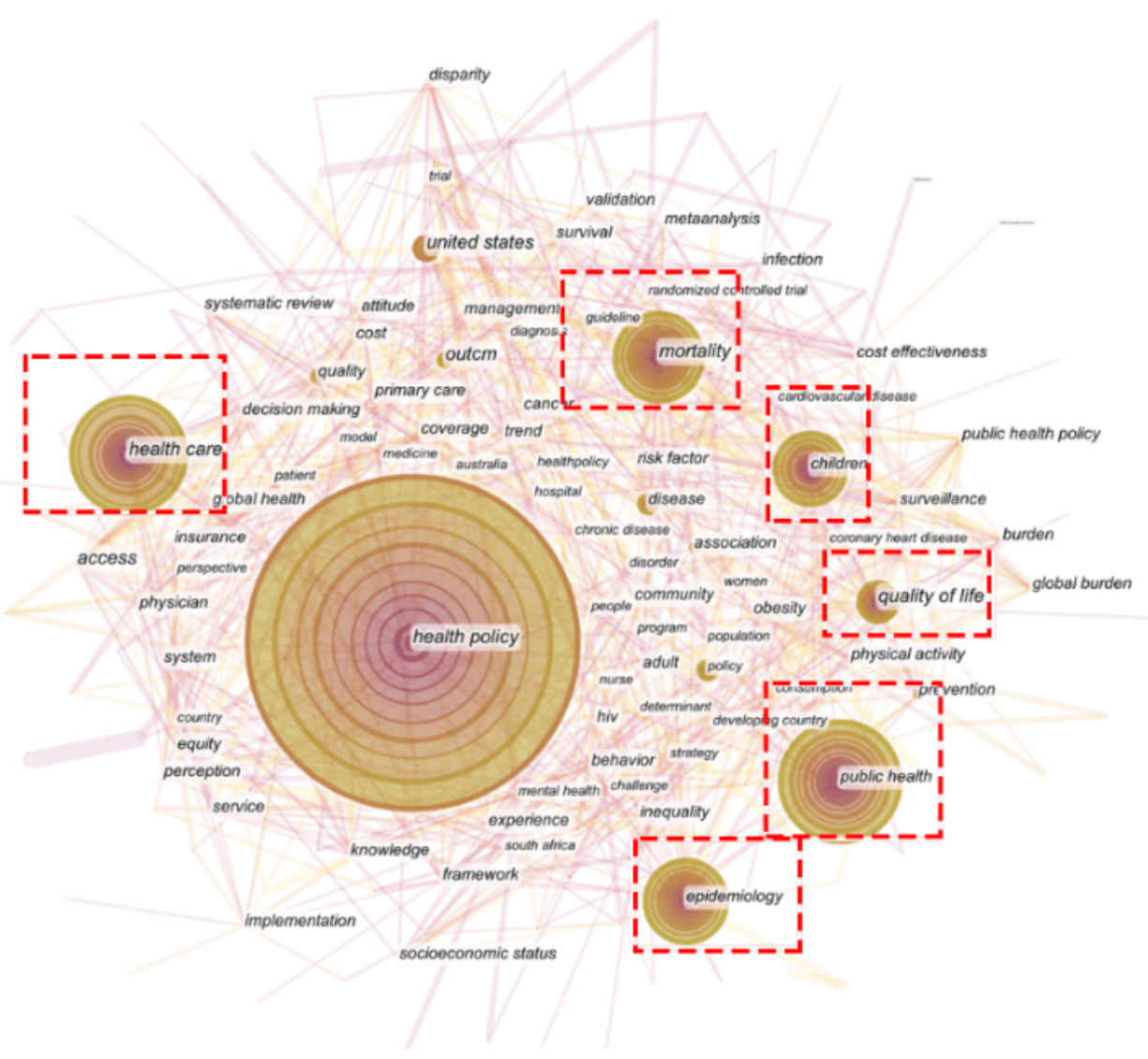

Figure 8

Key words co-appearance network

\begin{tabular}{|c|c|c|c|}
\hline \multirow{2}{*}{ Keywords } & \multirow{2}{*}{ Strength } & \multicolumn{2}{|c|}{ Begin-End } \\
\hline & & $2011-2015$ & $2016-2020$ \\
\hline influenza & 4. 47 & 믄- & 드- \\
\hline internet & 5.04 & 므는 & \\
\hline economics & 6.89 & & \\
\hline symptom & 5.13 & & \\
\hline me11itus & 5.59 & سمستس & \\
\hline law & 4. 79 & & \\
\hline comorbidity & 5.59 & - & \\
\hline violence & 4. 61 & 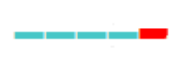 & \\
\hline smoking & 4. 78 & -1- & \\
\hline migrant & 6.30 & - & سשص- \\
\hline norway & 4. 90 & & \\
\hline statistics & 5.62 & 는 & שב-1- \\
\hline health equity & 10.57 & & - \\
\hline medical home & 8.09 & & \\
\hline telemedicine & 6.78 & 드는 & שسח-1 \\
\hline
\end{tabular}


Figure 9

the top 15 keywords with the strongest bursts between 2011 to 2020

Page 15/15 